\title{
Effect of One Week of Fibre Supplementation on Hunger and Satiety Ratings and Energy Intake
}

\author{
W. J. PASMAN and W. H. M. SARIS \\ Department of Human Biology, Maastricht University
}

\author{
M. A. J. WAUTERS \\ Department of Endocrinology and Human Nutrition, University Hospital, \\ Antwerp
}

\section{S. WESTERTERP-PLANTENGA}

Open University, Heerlen

\begin{abstract}
The effect of one week of supplementation with a water-soluble fibre (guar gum) was studied in obese women who had lost weight. In study $1(N=17$; mean $\pm S E M$ : age $38.5 \pm 2 \cdot 3 \mathrm{yrs}$; weight $86 \cdot 8 \pm 2 \cdot 3 \mathrm{~kg}$; BMI $32 \cdot 2 \pm 0 \cdot 9 \mathrm{~kg} . \mathrm{m}^{-2}$ ) energy intake and hunger and satiety scores were assessed under free-living conditions. In study 2 $\left(N=14\right.$; age $44.5 \pm 1 \cdot 8$ yrs; weight $78 \cdot 8 \pm 3 \cdot 1 \mathrm{~kg}$; BMI $\left.29.0 \pm 0.9 \mathrm{~kg} \cdot \mathrm{m}^{-2}\right)$ energy intake was fixed at $6 \mathrm{MJ}^{-d_{a y}{ }^{-1}}$ (their normal energy intake at that time) or $4 \mathrm{MJ} \mathrm{day}^{-1}$ (low energy intake). In both studies, the effect of one week of fibre supplementation ( $40 \mathrm{~g}$ in study 1 and $20 \mathrm{~g}$ in study 2 ) was compared with no supplementation. In study 1 , mean energy intake decreased significantly from $6 \cdot 7 \pm 0 \cdot 4 \mathrm{MJ}$ to $5 \cdot 4 \pm 0 \cdot 2 \mathrm{MJ}$ daily after fibre supplementation, while hunger and satiety scores did not change. At a low energy intake level of $4 \mathrm{MJ}$ given in study 2 , hunger scores were significantly decreased after fibre supplementation. No changes were seen in hunger and satiety scores during fibre supplementation at $6 \mathrm{MJ}$. The reduction in energy intake by soluble fibre under free living conditions and the hunger-reducing effect of fibre at the low energy intake level (4 MJ) suggests that fibre may be useful in the treatment of obesity, by facilitating compliance to low energy intake. $\quad$ (c) 1997 Academic Press Limited
\end{abstract}

\section{INTRODUCTION}

Successful weight maintenance is important because long-term weight reduction can be of considerable benefit to health in obese subjects by lowering risk factors for cardiovascular and other diseases (Goldstein, 1992; Wing \& Jeffery, 1995). So far the results from weight maintenance studies are very disappointing, with longterm success rates below 10-20\% (Garner \& Wooley, 1991). (Dex)fenfluramine (Wurtman et al., 1985), caffeine (Dulloo, Geissler, Horton, Collins \& Miller, 1989),

This study was financially supported by Sandoz Nutrition Ltd, Berne, Switzerland.

Address for correspondence: W. J. Pasman, University of Maastricht, Department of Human Biology, P.O. Box 616, 6200 MD Maastricht, The Netherlands. 
or a caffeine/ephedrine supplement (Astrup, Toubro, Cannon, Hein \& Madsen, 1991) have been shown to be useful agents with respect to maintenance of body weight. Bulking supplements such as dietary fibre increase feelings of fullness (Evans \& Miller, 1975; Leeds, 1987; Raben, Christensen, Holst \& Astrup, 1994) and augment satiating effects (Spiller, 1993; Ryttig, Tellnes, Haegh, Boe \& Fagerthun, 1989) and so reduce energy intake and body weight. Interventions with a high and low fibre meal, short-term and long-term interventions (breakfast - Burley, Leeds \& Blundell, 1987; breakfast-Delargy, Burley, O'Sullivan, Fletcher \& Blundell, 1995; all mealsDuncan, Bacon \& Weinsier, 1983; pre-loads before meals-Porikos \& Hagamen, 1986; van der Ven et al., 1994; long-term supplementation-Ryttig et al., 1989; Rigaud et al., 1990; Krotkiewski, 1984) all showed decreased hunger feelings and decreased energy intake when fibre was added.

Comparisons of the different fibre studies is, however, not easy. Variables like subjects (men or women; lean or obese), type of intervention (meal or pre-loads), laboratory or free living conditions, type of fibre used (soluble or insoluble), fibre dosage supplemented and duration of supplementation (short-term or long-term) are of importance for a good interpretation of the results found in the studies as is thoroughly discussed by Blundell and Burley (1987) and by Todd and coworkers (1990). Both emphasized that the type of administration used, an isolated fibre administered before a meal or administration of fibre via normal food products, like bread, as well as the water solubility of the fibre used, should be reported (Blundell \& Burley, 1987; Todd et al., 1990; Delargy et al., 1995).

Besides fibre specifications, the level of energy intake at which fibre supplementation takes place is of importance. In a study by Duncan and colleagues (1983) the satiating effect of fibre was investigated. Subjects were allowed to eat till satiation with different energy density diets (high and low energy density diet with low and high fibre contents resp.). Despite the same reported levels of satiation, energy intake was lower in the high fibre diet than it was in the low fibre diet (1570 vs. $3000 \mathrm{kcal})$. The concept of time-energy displacement based on the hypothesis that prolonged eating time at a high fibre diet will induce satiety at a low energy intake level was therefore supported (Duncan et al., 1983). When a fixed low level of energy intake is consumed, it was found that $30 \mathrm{~g}$ of plant fibre daily, effectively reduced hunger feelings (Astrup et al., 1990). They compared the hunger feelings during a very low calorie diet (VLCD) compared with a VLCD without fibre supplementation. Their finding showed that fibre supplementation is applicable in the field of obesity. No differences were found in weight losses between the fibre supplemented and non-fibre supplemented group, but the reduced hunger feelings in the fibre supplemented group may improve compliance to the VLCD (Astrup et al., 1990). Supplementation of a bulking agent such as fibre could therefore be of interest for the possibility to maintain a decreased energy intake in order to prevent weight gain. However, usefulness of fibre supplementation in the long-term to achieve weight maintenance under non-restricted conditions is not clear (Evans \& Miller, 1975; Hylander \& Rössner, 1983; Rigaud et al., 1990).

In this study we used a partially hydrolyzed form of guar gum fibre in powder form which enabled us to give a high dosage of fibre daily, because it could be dissolved in drinks. In the present study the fibre isolate was dissolved in a waterorange juice solution. Guar gum, obtained from the endosperm of the Indian cluster bean Cyamopsis tetragonolobus, is a galactomannan, which in contact with water forms a highly viscous gel (Todd et al., 1990). Guar gum was used because it delays 
gastric emptying (Anderson, 1986; Todd et al., 1990) which might result in decreased hunger (what was indeed found with this supplement by van der Ven et al., 1994), increased satiety (Leeds, 1987) and decreased energy intake (Evans \& Miller, 1975). Because most of the studies carried out with fibre are short-term interventions of only one day, we investigated whether supplementation with guar gum fibre under free living conditions decreased energy intake and/or hunger and satiety feelings at the end of one week of supplementation. In a second study the effect of fibre supplementation were studied at normal (6 MJ) and low (4 MJ) levels of energy intake level.

\section{METHODS}

\section{Subjects}

In the first study 17 women participated (mean \pm SEM: age $38 \cdot 5 \pm 2 \cdot 3$ yrs; weight $86.8 \pm 2.3 \mathrm{~kg}$; height $1.64 \pm 0.01 \mathrm{~m}$; BMI $\left.32.2 \pm 0.9 \mathrm{~kg} \cdot \mathrm{m}^{-2}\right)$. In the second study, 14 female subjects took part (mean age $44.5 \pm 1 \cdot 8 \mathrm{yrs}$; weight $78.8 \pm 3.1 \mathrm{~kg}$; height $1.63 \pm 0.02 \mathrm{~m}$; BMI $29 \cdot 0 \pm 0.9 \mathrm{~kg} \cdot \mathrm{m}^{-2}$ ), four of whom had participated in study 1 . All subjects were studied 3 months after losing approximately $10 \mathrm{~kg}$ of body weight during a 2-month treatment with very low calorie diet for their obesity. This postweight loss period was selected since it was hypothesized that subjects should be more vulnerable to weight gain after VLCD. The studies were approved by the Ethics Committee of the Maastricht University and all subjects gave their written informed consent.

\section{Study 1}

Study design

The effect of fibre supplementation on energy intake and on ratings of hunger and satiety was compared with a normal, non-supplemented fibre condition. Subjects were studied for two periods of one week. During both weeks, subjects were asked not to eat between their three main meals. In one week, subjects' diet was supplemented with $20 \mathrm{~g}$ of fibre twice daily and the other week was considered as control with no intervention. The fibre supplement was randomised across subjects between the first and second weeks. During the last three days of the week, the food intake was recorded in a food diary.

\section{Procedure}

Subjects were instructed to eat their normal main meals and to refrain from snacks in between meals during both weeks. Instead of snacks, subjects were asked to consume an orange juice solution at $15.30 \mathrm{~h}$ in the afternoon and at $20.00 \mathrm{~h}$ in the evening. During the non-supplemented week plain orange juice was consumed, whereas during the fibre supplemented week $20 \mathrm{~g}$ of fibre was dissolved in the orange juice solution ( $40 \mathrm{~g}$ of fibre daily). Energy intake (from coffee, tea or soft drinks) in between the main meals was zero giving the opportunity to study the effect of fibre supplementation on the amount ingested during the main meals and at hunger and satiety scores. Feelings of hunger and satiety were scored using rating scales (see below). Fibre supplementation was not blinded. Supplementation of the sachets with fibre enabled the subjects to prepare their drink everywhere. 


\section{Food intake diary}

Dietary intake was recorded for the last three days of the study weeks in a food intake diary. Personal instruction was given in advance by a trained dietitian. After returning the diaries a final check completed the information to reduce underreporting. Portion size and household attributes were examined to give a good indication of the amount of food consumed. Food consumption was converted into energy and macronutrient intake using a computer programme based upon a nutrient file compiled from the Dutch food composition table (NEVO, 1989).

\section{Rating scales}

Feelings of hunger and satiety were scored at fixed times during the day on 100$\mathrm{mm}$ lines anchored at the ends with "very hungry" and "not hungry at all" or "very satiated" and "not satiated at all". The times of rating were before $(7.00 \mathrm{~h})$ and after $(7.30 \mathrm{~h})$ breakfast, in between meals in the morning $(10.30 \mathrm{~h})$, before $(12.00 \mathrm{~h})$ and after $(12.30 \mathrm{~h})$ lunch, in between meals in the afternoon $(15.30 \mathrm{~h})$, before $(18.00 \mathrm{~h})$ and after $(18.30 \mathrm{~h})$ dinner and in the evening $(20.30 \mathrm{~h})$.

\section{Fibre supplementation}

Subjects were randomly assigned to start either with or without fibre supplementation. Fibre was consumed for four days prior to the 3-day measurement period to allow the subjects to get used to supplementation. The fibre was a watersoluble fraction and partially hydrolyzed guar gum (Benefiber ${ }^{\circledR}$, Sandoz Nutrition, Minneapolis). A total of $40 \mathrm{~g}$ was consumed: $20 \mathrm{~g}$ of fibre twice daily, dissolved in orange juice. The subjects had to prepare the orange juice solution $(200 \mathrm{ml})$ with $20 \mathrm{~g}$ of fibre in the afternoon and in the evening by themselves. The composition of the drink when fibre was added was: energy $308 \mathrm{~kJ}, 1.0 \mathrm{~g}$ protein, no fat, $17.4 \mathrm{~g}$ of carbohydrate, $1.6 \mathrm{~g}$ of orange fibre and $20 \mathrm{~g}$ of guar gum.

\section{Study 2}

\section{Study design}

Two fixed levels of energy intake were compared when fibre was supplemented vs. a non-supplemented situation. During four weeks, subjects were exposed in random order to four different conditions. Two fixed energy intake levels (4 and $6 \mathrm{MJ}$ ) were compared with fibre supplementation and without fibre supplementation. Each condition was carried out for one week, during the last three days on which feelings of hunger and satiety were scored.

\section{Procedure}

The energy intake level was fixed at $4 \mathrm{MJ}$ and $6 \mathrm{MJ}$, using different complete menus. Several options for breakfast, lunch and dinner and drinks to be consumed between meals, were completely prescribed. Subjects were able to choose and prepare their favorite food items, but were asked to stick to the prescribed amounts of food and to the given recipes, to maintain the energy intake levels. The macronutrient composition and energy content of each menu was the same. Within each level the total energy intake was obtained with the breakfast, lunch and dinner suggestions made. Supplementation of fibre was carried out by solving two times daily $10 \mathrm{~g}$ of 
fibre in orange juice. The drink was consumed in the afternoon $(15.30 \mathrm{~h})$ and in the evening $(20.00 \mathrm{~h})$. Fibre supplementation was randomised as was the energy intake level across subjects among the 4 weeks; one week at the $4 \mathrm{MJ}$ level and for one week at the $6 \mathrm{MJ}$ level with or without fibre. During the last three days of the week with fibre supplementation and without fibre supplementation, hunger and satiety scores were studied.

\section{Menu method}

The energy intake level was kept fixed at $4 \mathrm{MJ}$ and $6 \mathrm{MJ}$ using different complete menus. The $4 \mathrm{MJ}$ menu contained 21 percent of energy ( $\mathrm{E} \%$ ) from protein, $24 \mathrm{E} \%$ fat, $55 \mathrm{E} \%$ carbohydrate and $19 \mathrm{~g}$ of dietary fibre. The $6 \mathrm{MJ}$ menu contained $19 \mathrm{E} \%$ protein, $28 \mathrm{E} \%$ fat, $53 \mathrm{E} \%$ carbohydrate and $21 \mathrm{~g}$ of dietary fibre. Breakfast, lunch and dinner and in between drinks were completely prescribed on paper, qualitatively and quantitatively, to enable the subjects to prepare their meals at home. Subjects could choose daily between different menus and the main meals could also be switched from one menu to the other within one energy intake level, so that subjects were relatively free to choose their favorite food items. Within each energy intake level the total energy intake was obtained with the breakfast, lunch and dinner suggestions made. Compliance to the menus prescribed was checked. Subjects were asked to write down on the menu which food items were not eaten, or were consumed in larger quantities. The fixed levels of energy intake were based upon the food intake diaries of these post-weight loss subjects. Because the subjects were in a postweight loss phase ( 3 months after a very low calorie diet) they were not able to consume the amount normally necessary for weight maintenance. The analyses of their food intake diaries showed a mean energy intake of $5.4 \mathrm{MJ}$ at 2 months after the VLCD. This value is very low, especially when related to their resting metabolic rate (data not shown), and underreporting could be a realistic explanation (Pannemans \& Westerterp, 1993). In a pilot experiment the $7 \mathrm{MJ}$ energy intake level (based upon resting metabolic rate and activity level) was tested. Because the subjects complained about the quantity of food that had to be consumed with $7 \mathrm{MJ}$, we decided to lower the energy intake level to $6 \mathrm{MJ}$. Because a clear discrepancy in energy intake level is necessary to show effects on feelings of hunger and satiety (and an effect of fibre) the low energy intake level was set at $4 \mathrm{MJ}$ instead of the proposed $5 \mathrm{MJ}$.

\section{Rating scales}

Hunger and satiety feelings were scored during the day at fixed times on a 100$\mathrm{mm}$ line (see study 1). In the second study two further assessments of hunger and satiety were made. In the afternoon and in the evening subjects were asked to score hunger and satiety feelings before and after consumption of the orange juice $(+/-$ fibre) solution ( $15.00 \mathrm{~h}$ and $20.00 \mathrm{~h})$.

\section{Fibre supplementation}

The type of fibre supplemented in the second study was the same as in the first study. The amount supplemented differed; in the second study subjects consumed two times $10 \mathrm{~g}$ of Benefiber ${ }^{\circledR}$ daily, instead of $20 \mathrm{~g}$ two times daily as performed in study 1 . In study 2 fibre supplementation was not blinded either. Supplementation of the sachets with fibre enabled the subjects to prepare their drink everywhere. 


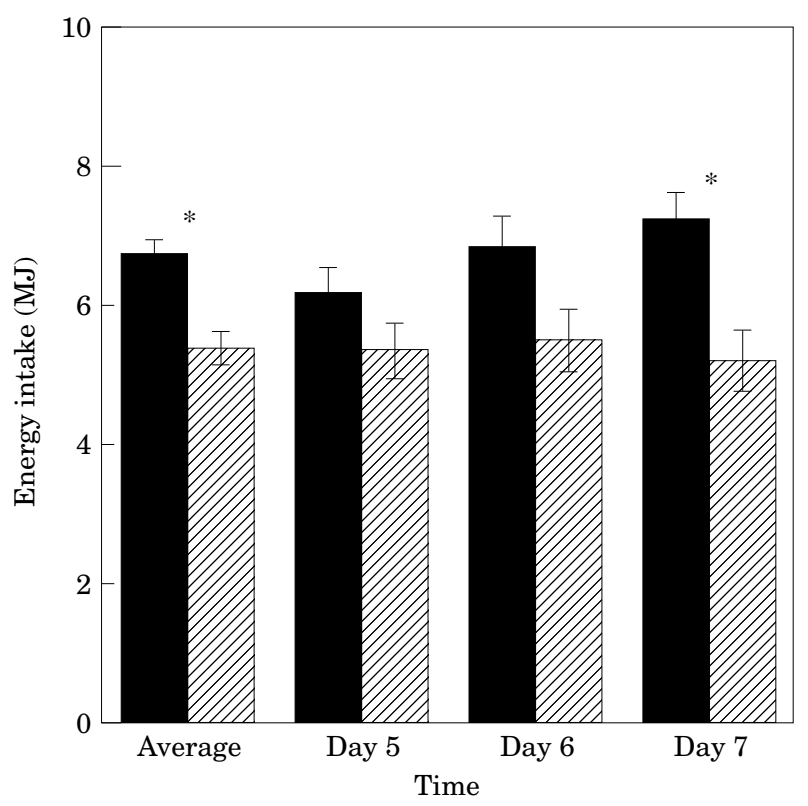

FIGURE 1. Mean daily energy intake (MJ) over 3 days of 17 post-obese females on nonsupplemented days ( $\mathbf{\square})$ and on days with $20 \mathrm{~g}$ of fibre supplement twice daily (田) in study 1 . $* p<0 \cdot 05$.

\section{Data analysis}

A two-way Anova (repeated measurements) was used to test for differences between the fibre and non-supplemented fibre conditions at the different time points (not the mean values). The data are presented as mean and standard errors of the mean $(S E M)$.

\section{RESULTS}

\section{Study 1}

Energy intake was significantly lower when fibre supplement was eaten for three days than on three non-supplemented days (fibre intake mean $\pm S E M 20 \pm 8 \mathrm{~g}$ daily). When an additional $40 \mathrm{~g}$ of fibre was consumed daily, energy intake (averaged over three days) was significantly lower $(5 \cdot 4 \pm 0.24 \mathrm{MJ})$ than on the control days $(6 \cdot 7 \pm 0 \cdot 39 \mathrm{MJ})$ (Fig. 1), $F(1,48)=8 \cdot 32, p<0 \cdot 05$. Hunger and satiety scores averaged for each time point over three days were the same for fibre and non-supplemented days (Fig. 2), hunger $F(1,73)=0 \cdot 007, p>0 \cdot 9$, satiety $F(1,73)=2 \cdot 67, p=0 \cdot 11$. Two subjects complained about flatulence during the fibre supplemented week.

\section{Study 2}

Reported food intake at the $6 \mathrm{MJ}$ level was (mean $\pm S E M) 5 \cdot 68 \pm 0 \cdot 07 \mathrm{MJ}$ and at the $4 \mathrm{MJ}$ level $3.98 \pm 0.03 \mathrm{MJ}$. Hunger scores were significantly lower on the $6 \mathrm{MJ}$ menu than on the $4 \mathrm{MJ}$ menu without fibre supplementation, $F(1,65)=3 \cdot 94$, 

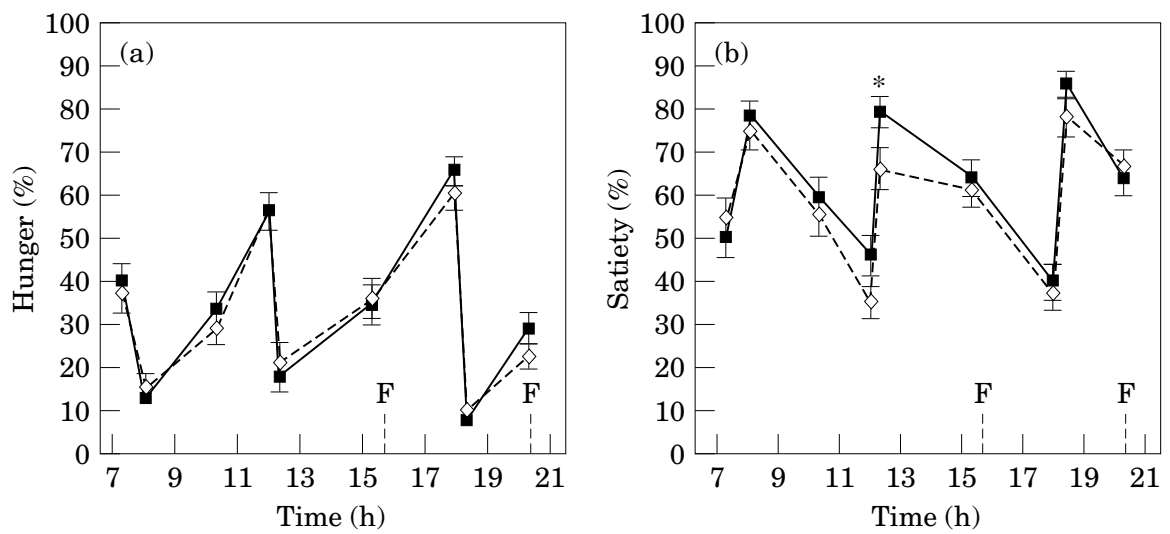

FIGURE 2. Hunger scores (a) and satiety scores (b) averaged for the three days without supplement $(\boldsymbol{\square})$ and with fibre supplementation $(\diamond)$ in study 1 . Consumption of fibre indicated by F. $* p<0 \cdot 05$.
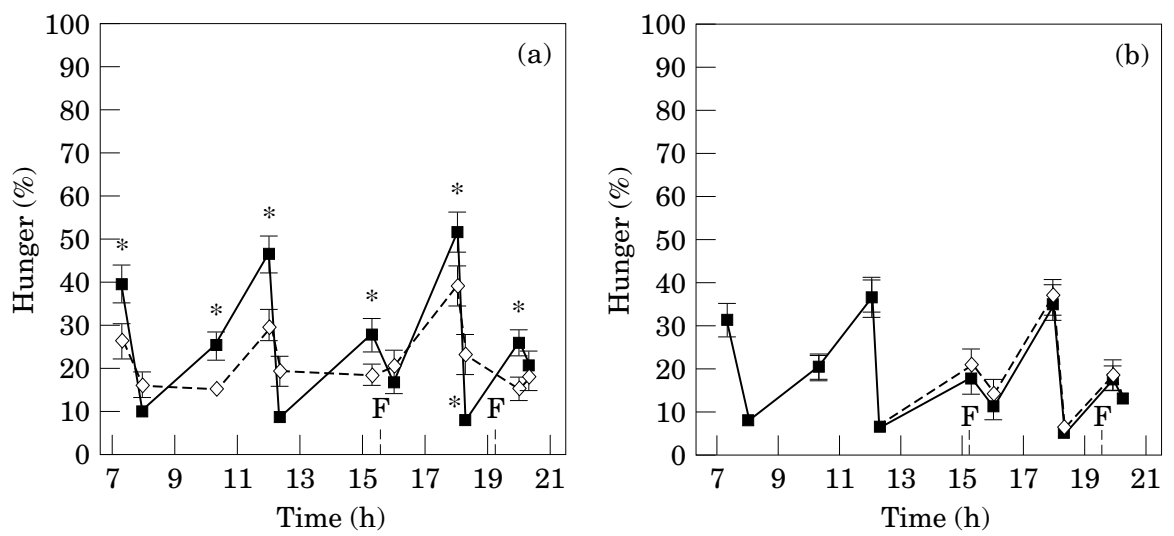

Figure 3. Hunger scores $(N=13)$ at energy-intake levels of $4 \mathrm{MJ}$ (a) and $6 \mathrm{MJ}$ (b) averaged for the three days without supplement $(\boldsymbol{\square})$ and for the three fibre-supplemented days $(\diamond)$ in study 2 . Consumption of fibre indicated by F. * $p<0 \cdot 05$.

$p=0.05$. Hunger (Fig. 3) and satiety (Fig. 4) scores were the same with and without fibre supplementation at the $6 \mathrm{MJ}$ level, $F(1,51)=0 \cdot 26, p=0 \cdot 61$. At the low energy intake level of $4 \mathrm{MJ}$, hunger scores and satiety scores were not significantly different according to a two-way Anova $F(1,73)=0 \cdot 88, p=0 \cdot 35$ for hunger, and for satiety $F(1,70)=1 \cdot 85, p=0 \cdot 18$. Data sets were, however, not fully complete for Anovaanalysis, and therefore a paired $t$-test was performed to investigate differences between time points. The time points that differed significantly for hunger were: $7.00 \mathrm{~h}(t=3.42, p<0.01) ; 12.00 \mathrm{~h}(t=2.33, p<0.05) ; 20.00 \mathrm{~h}(t=2.38, p<0.05)$ and $20.30 \mathrm{~h}(t=2 \cdot 23, p<0 \cdot 05)$. For satiety the time points that differed significantly were: $7.00 \mathrm{~h}(t=3 \cdot 34, p<0 \cdot 01) ; 12.00 \mathrm{~h}(t=2 \cdot 50, p<0 \cdot 05)$ and $20.30 \mathrm{~h}(t=2 \cdot 10, p<0 \cdot 05)$. 

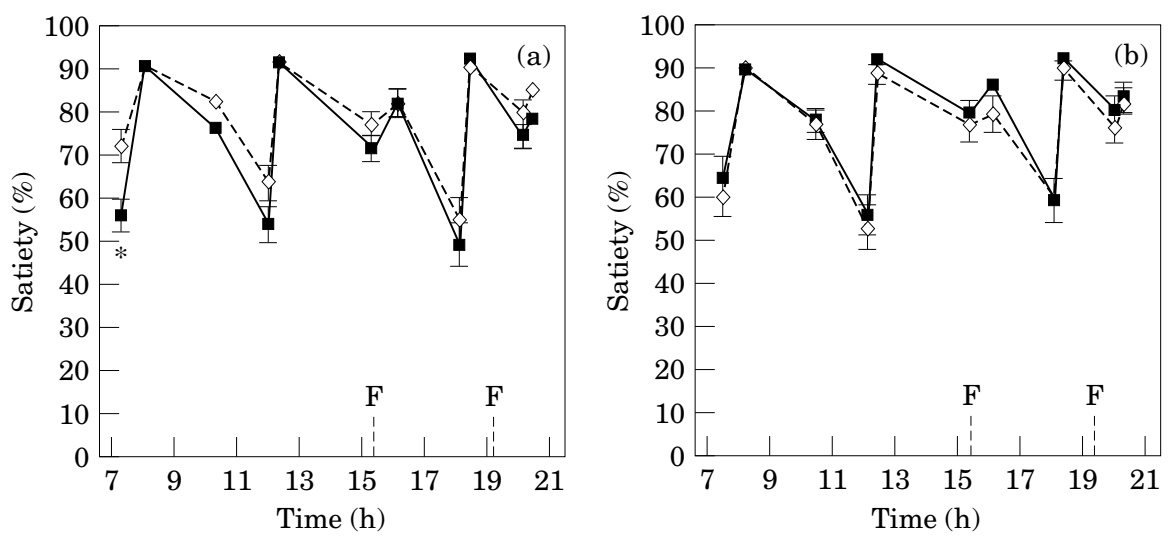

FigURE 4. Satiety scores $(N=13)$ at energy-intake levels of $4 \mathrm{MJ}$ (a) and $6 \mathrm{MJ}$ (b) averaged for the three days without supplement $(\boldsymbol{\square})$ and for the three fibre-supplemented days $(\diamond)$ in study 2 . Consumption of fibre indicated by F. ${ }^{*} p<0 \cdot 05$.

\section{Discussion}

The reduced energy intake with fibre supplementation under free living conditions and the lowered hunger scores and increased satiety scores at a fixed low level of energy intake, are the main findings of the two studies. The fibre supplement used was safe and easy to consume in high amounts, and could be dissolved by the subjects everywhere.

\section{Study 1}

In the present study a reduction of $19 \%$ in energy intake was found for freely feeding obese females when fibre intake was increased from the normal $20 \pm 8 \mathrm{~g}$ daily to $56 \pm 7 \mathrm{~g}$. Evans and Miller (1975) reported a reduction in energy intake of $10 \%$ on average for all subjects and a reduction of $30 \%$ for the obese subjects $(N=3)$, when $10 \mathrm{~g}$ of guar gum fibre was taken twice daily for one week. The subjects were instructed to consume the fibre with a glass of water half an hour before the main meal in contrast to our study were subjects consumed the fibre supplement in between main meals. Because both studies found lowering of energy intake it suggests that timing is not that important for an effective decrease in energy intake. Our results are based on 17 obese women vs. 3 obese (no gender reported) in the study of Evans and Miller (1975). As in our study their subjects could eat ad libitum, under free living conditions. However, their food intake diaries were based upon weighed food intakes, resulting in better energy intake calculations, but having the negative effect that subjects might become more aware of their food consumption and consequently lower their intake. Duncan and colleagues (1983) also found lowered energy intake with high fibre containing diets in laboratory situations. Krotkiewski (1984) found lowered body weights in the obese women participating in a ten week supplementation trial of $20 \mathrm{~g}$ of guar gum fibre. They probably lowered their energy intake although the subjects were under free living conditions. Our results confirm his findings and add that spontaneous food consumption is significantly lower with fibre supplementation. 


\section{Study 2}

The finding in the second study that fibre supplementation effectively reduced hunger scores and increased satiety scores at the $4 \mathrm{MJ}$ level is promising with respect to long-term weight maintenance. Reduced hunger feelings during a very low calorie diet (VLCD) as reported by Astrup and colleagues (1990) when subjects were supplemented with fibre may improve compliance to the VLCD. The comparable hunger and satiety ratings found at the $6 \mathrm{MJ}$ level suggests that our subjects were already fully satiated and not hungry at all, at this relatively high level of energy intake. Additional fibre supplementation is then of no benefit. Three months prior to these two studies described all subjects had participated in a VLCD. Supplementation of a bulking agent such as fibre could therefore be of special interest to these post-weight loss subjects, for a better compliance to a low energy intake and for maintenance of a decreased energy intake in order to prevent weight gain.

We can conclude that fibre supplementation is effective to realise a low energy intake level spontaneously without hunger feelings. It further appears to be rather successful to keep a fixed reduced energy intake level, when fibre is supplied.

\section{Methodological Remarks}

The hunger and satiety scores in this study show a clear discrepancy in the case of normal weight subjects. Lean counterparts have a wider range in hunger scores and score higher $(40-100 \mathrm{~mm}$ ) (van der Ven et al., 1994) than the subjects in this study $(10-45 \mathrm{~mm})$. The post-weight loss phase might be an explanation for the exaggerated satiety and suppressed hunger responses. Different responses between obese and lean subjects also have been mentioned in other studies (Evans \& Miller, 1975; Porikos \& Hagamen, 1986; Duncan et al., 1983), suggesting that this group of subjects might benefit most of fibre supplementation.

The fibre isolate used in the present studies enabled us to administer a high dosage of fibre daily. The sachets with guar gum powder were easy to take away and could be dissolved in drinks. The supplement proved to be a practical and safe way to increase fibre intake daily in freely feeding subjects.

A new method for intake of a fixed amount of food was used, the menu method, described in study 2 . In comparison with food administration or the double portions technique, for control of energy intake, the method described was a very practical way of feeding subjects at a fixed energy level under free living conditions. Subjects were able to choose almost freely and use normal food items. The menu method is less time consuming for the investigators and subjects. The laboratory setting is not necessary, giving a more reliable response of hunger and satiety scores than under laboratory conditions. In comparison with the double portion technique, the menu method is not laborious. Especially for relatively short-term studies of 1 day to 1-2 weeks this menu method could be used, because the compliance was very high (95-99\%). Applicability in the long-term however has to be investigated.

In conclusion, the reduction in energy intake by fibre under free living conditions and the hunger-reducing effect of fibre at the low energy intake level (4 MJ) suggests that soluble fibre may be useful in weight maintenance, if it can be ingested daily in the long-term, by facilitating compliance to low energy intake. 


\section{REFERENCES}

Anderson, J. W. (1986). Fiber and health: An overview. American Journal of Gastroenterology, 81, 892-897.

Astrup, A., Vrist, E. \& Quaade, F. (1990). Dietary fiber added to very low calorie diet reduces hunger and alleviates constipation. International Journal of Obesity, 14, 105-112.

Astrup, A., Toubro, S., Cannon, S., Hein, P. \& Madsen, J. (1991). Thermogenic synergism between ephedrine and caffeine in healthy volunteers: A double-blind, placebo-controlled study. Metabolism, 40, 323-329.

Blundell, J. E. \& Burley, V. J. (1987). Satiation, satiety and the action of fibre on food intake. International Journal of Obesity, 11 (Suppl. 1), 19-25.

Burley, V. J., Leeds, A. R. \& Blundell, J. E. (1987). The effect of high and low-fibre breakfasts on hunger, satiety and food intake in a subsequent meal. International Journal of Obesity, 11 (Suppl. 1), 87-93.

Delargy, H. J., Burley, V. J., O’Sullivan, K. R., Fletcher, R. J. \& Blundell, J. E. (1995). Effects of different soluble:insoluble fibre ratios at breakfast on 24-h pattern of dietary intake and satiety. European Journal of Clinical Nutrition, 49, 754-766.

Dulloo, A. G., Geissler, C. A., Horton, T., Collins, A. \& Miller, D. S. (1989). Normal caffeine consumption: influence on thermogenesis and daily energy expenditure in lean and postobese human volunteers. American Journal of Clinical Nutrition, 49, 44-50.

Duncan, K. H., Bacon, J. A. \& Weinsier, R. L. (1983). The effects of high and low energy density diets on satiety, energy-intake and eating time of obese and non-obese subjects. American Journal of Clinical Nutrition, 37, 763-767.

Evans, E. \& Miller, D. S. (1975). Bulking agents in the treatment of obesity. Nutrition Metabolism, 18, 199-203.

Garner, D. M. \& Wooley, S. C. (1991). Confronting the failure of behavioral and dietary treatments for obesity. Clinical Psychology Review, 11, 729-780.

Goldstein, D. J. (1992). Beneficial effects of modest weight loss. International Journal of Obesity, 16, 397-415.

Hylander, B. \& Rössner, S. (1983). Effects of dietary fiber intake before meals on weight loss and hunger in a weight-reducing club. Acta Medica Scandinavica, 213, 217-220.

Krotkiewski, M. (1984). Effect of guar gum on body-weight, hunger ratings and metabolism in obese subjects. British Journal of Nutrition, 52, 97-105.

Leeds, A. R. (1987). Dietary fibre: mechanism of action. International Journal of Obesity, 11 (Suppl. 1), 3-7.

Nederlandse Voedingsstoffenbestand (NEVO). (1989). Dutch nutrient database 1989/1990. Zeist, The Netherlands: Stichting NEVO [in Dutch]

Pannemans, D. L. E. \& Westerterp, K. R. (1993). Estimation of energy-intake to feed subjects at energy balance as verified with doubly labelled water: a study in the elderly. European Journal of Clinical Nutrition, 47, 490-496.

Porikos, K. \& Hagamen, S. (1986). Is fiber satiating? Effects of a high fiber preload on subsequent food intake of normal-weight and obese young men. Appetite, 7, 153-162.

Raben, A., Christensen, N. J., Holst, J. J. \& Astrup, A. (1994). Decreased postprandial thermogenesis and fat oxidation but increased fullness after a high-fiber meal compared with a low-fiber meal. American Journal of Clinical Nutrition, 59, 1386-1394.

Rigaud, D., Ryttig, K. R., Angel, L. A. \& Apfelbaum, M. (1990). Overweight treated with energy restriction and a dietary fibre supplement: a 6-month randomized, double-blind, placebo-controlled trial. International Journal of Obesity, 14, 763-769.

Ryttig, K. R., Tellnes, G., Haegh, L., Boe, E. \& Fagerthun, H. (1989). A dietary fiber supplement and weight maintenance after weight reduction: a randomized, double-blind placebo-controlled long-term trial. International Journal of Obesity, 13, 165-171.

Spiller, G. A. (1993). Handbook of dietary fiber in human nutrition (2nd edition). CRC Press: Baco Raton, LA, U.S.A.

Todd, P. A., Benfield, P. \& Goa, K. L. (1990). Guar Gum. A review of its pharmacological properties, and use as a dietary adjunct in hypercholesterolaemia. Drugs, 39, 917-928.

van der Ven, M. L. H. M., Westerterp-Plantenga, M. S., Wouters, L. \& Saris, W. H. M. (1994). Effects of liquid preloads with different fructose/fibre concentrations on subsequent food intake and ratings of hunger in women. Appetite, 23, 139-146. 
Wing, R. R. \& Jeffery, R. W. (1995). Effect of modest weight loss on changes in cardiovascular risk factors: are there differences between men and women or between weight loss and maintenance? International Journal of Obesity, 19, 67-73.

Wurtman, J., Wurtman, R., Mark, S., Tsay, R., Gilbert, W. \& Gordon, J. (1985). Dexfenfluramine selectively suppresses carbohydrate snacking by obese subjects. International Journal of Eating Disorders, 4, 89-99.

Received 16 May 1996, revision 17 February 1997 